\title{
SEALING ANALYSIS TROUGH COMPUTATIONAL SIMULATION COMPARING ASSEMBLY CONDITIONS OF DIESEL INJECTOR AT TEST BENCH AND AT ENGINE
}

\author{
João G. Farias ${ }^{1}$, Rodrigo Pedroso ${ }^{1}$ e Claudio Gorz ${ }^{1}$ \\ ${ }^{1}$ Robert BOSCH Ltda. \\ E-mails: joao.farias@br.bosch.com, rodrigo.pedroso@br.bosch.com e \\ claudio.gorz@br.bosch.com
}

\begin{abstract}
Normally diesel injectors are tested with higher internal pressure levels at test bench than usual at work conditions, to verify any possible leakage regarding process deviation. During this test, some injectors shown micro leakage at interface between injector and nozzle bodies. However, the same injectors do not show leakage when assembled at engines. Besides the higher internal pressure levels, the assembly condition at test bench is different than at engines. At engines, there is an additional assembly load coming from the screwing force of the injector at engine block. Finite element analyses were performed to verify the sealing at the interface where the micro leakage was identified, comparing both assembly conditions under normal working conditions and with higher loading levels, according to the applied at test bench. These studies show the possibility of leakage when assembled at test bench, due to the missing of injector assembly load and the higher applied internal pressure level. Therefore, it was validated the injector robustness when assembled at engines, even under higher pressure levels than normal working condition. Improvements at assembly conditions at test bench will be implemented in order to reduce the leakage possibility and to approximate the real assembly condition at engines.
\end{abstract}

\section{INTRODUCTION}

Leakage tests with higher internal pressure levels than usual under working conditions are performed at diesel injectors in order to verify any possibility of leakage regarding process deviations. During this test, some injectors shown micro leakage at interface between injector and nozzle bodies. However, this injectors did not show any leakage under working conditions at engines. As mentioned, the internal pressure levels are different at tests and at engines, besides that the assembly loads are also different.

In order to understand the sealing at interface where the micro leakage was identified, finite element analyzes were performed comparing both test bench and engine assembly and loading conditions. 


\section{NUMERICAL MODELS}

For both test bench and engine analyses, full tridimensional numerical models with deformed parts of injector, with linear elastic behavior, and rigid parts of test bench and engine were used. Only the boundary conditions and loads were different.

Picture 1 shows the injector, composed by the body, nozzle body, nozzle nut and seal ring, and the rigid surface in place of the test bench and engine interface.

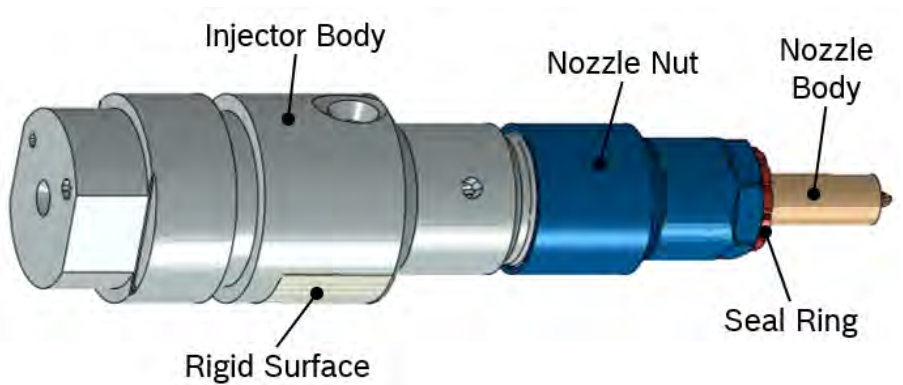

Picture 1 - Parts of finite element model.

\subsection{Test bench model}

Picture 2 shows the boundary conditions and loads used for the test bench model. Both minimal $\left(F_{\text {nut_min }}\right)$ and maximal $\left(F_{\text {nut_max }}\right)$ assembly forces of nozzle nut and different internal pressure levels were evaluated. At test bench, the high pressure connector force ( $\left.F_{H P C}\right)$ is the only force to assembly the injector at test bench.

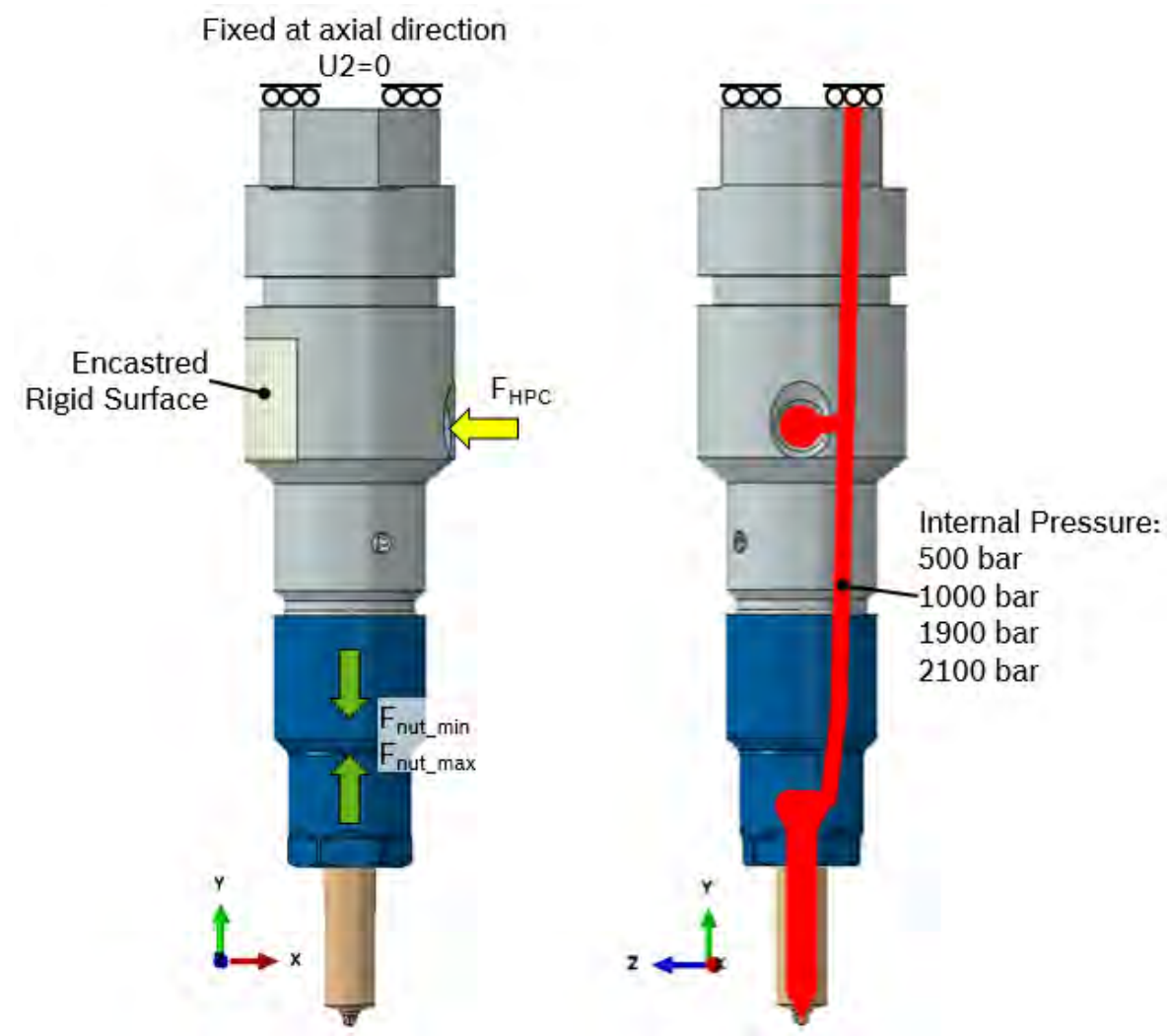

Picture 2 - Boundary conditions and load of test bench model. 


\subsection{Engine model}

For the engine model, the differences are the additional clamping force to assembly the injector at engine block, also considered under minimal ( $\left.F_{\text {clamp_min }}\right)$ and maximal ( $\left.F_{\text {clamp_max }}\right)$ values, and the internal pressure of 1800 bar, which is the peak pressure under working conditions. Picture 3 shows the boundary conditions and loads used for the engine model.

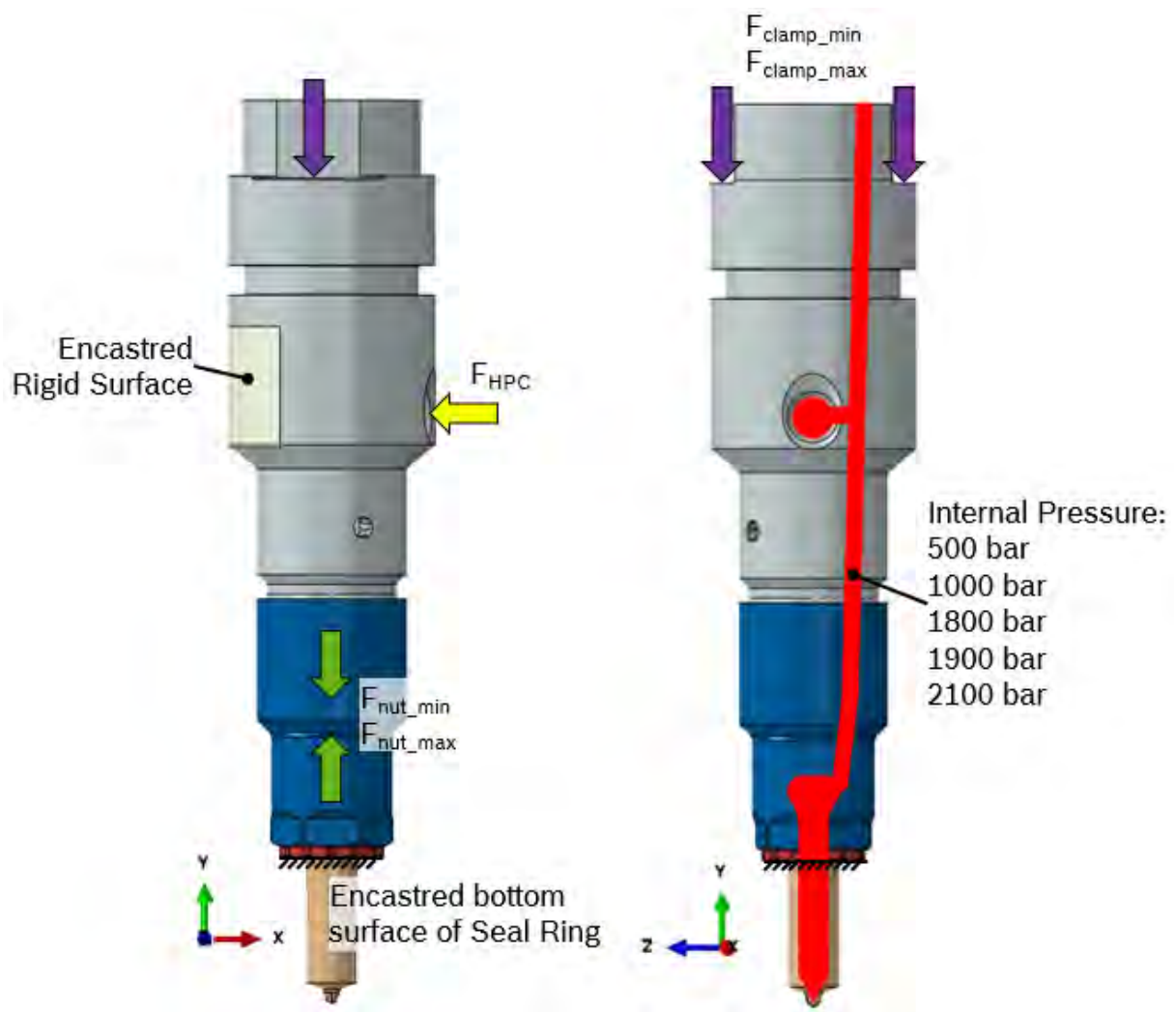

Picture 3 - Boundary conditions and load of engine model.

\section{RESULTS}

The micro leakage was identified under leakage test at interface between injector and nozzle bodies. Because this, the sealing was evaluated through the contact pressure at critical path aligned with high pressure bore at nozzle body surface, as shown in Picture 4.

The contact pressure along the critical path was got from each evaluated condition at test bench and engine models and the values were compared with the applied internal pressure and the safety limit, equal to 1,5 times the applied internal pressure. If more than half of contact length has contact pressure values smaller than the applied internal pressure, leakage problems are expected. If contact pressure values are higher than applied internal pressure, but smaller than safety limit, risk of leakage is observed. However, if the contact pressure values of at least half of contact length are higher than safety limit, the sealing function is achieved. This procedure is schematically shown in Picture 5. 


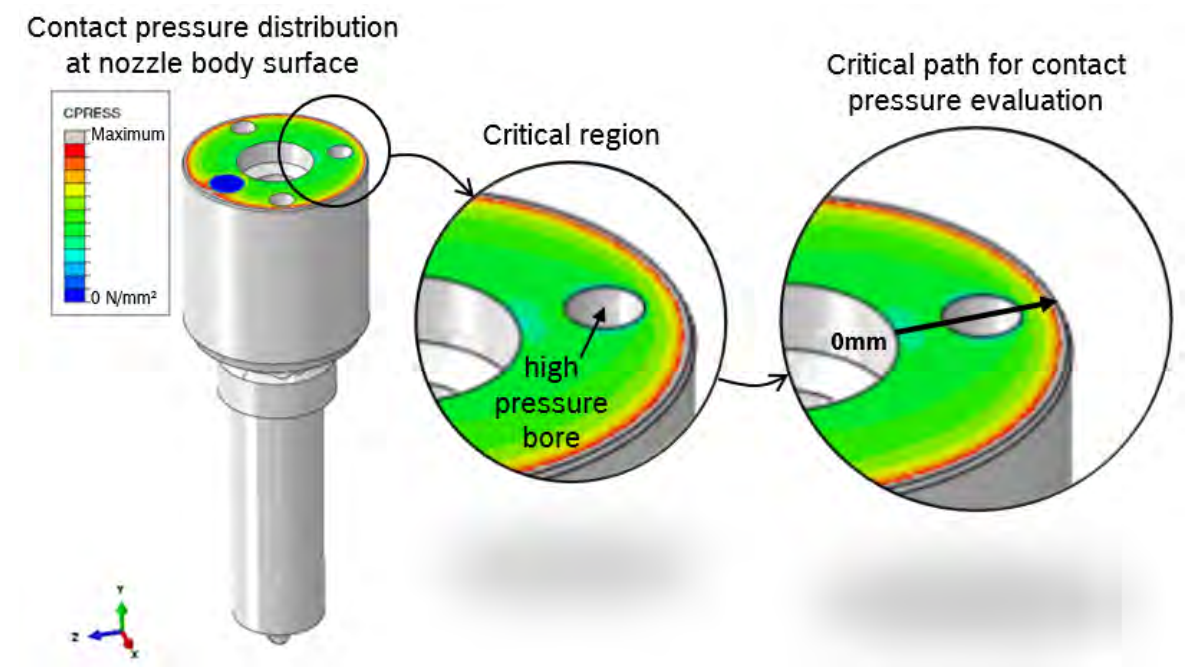

Picture 4 - Evaluated sealing region at nozzle body surface, showing the critical path.

(a) Leakage

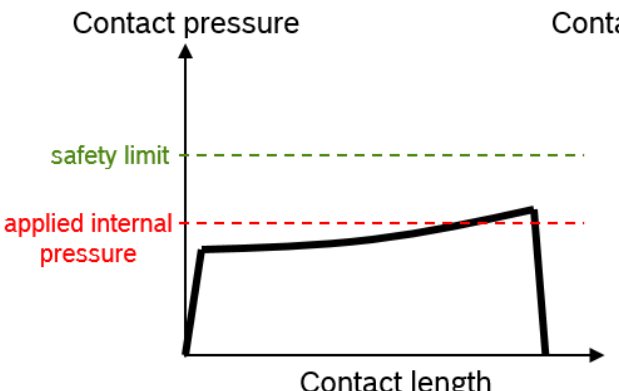

(b) Risk of Leakage Contact pressure

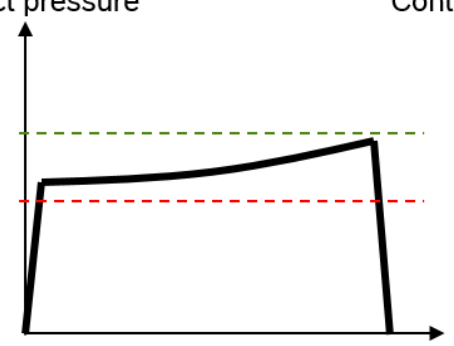

Contact length (c) No Leakage

Contact pressure

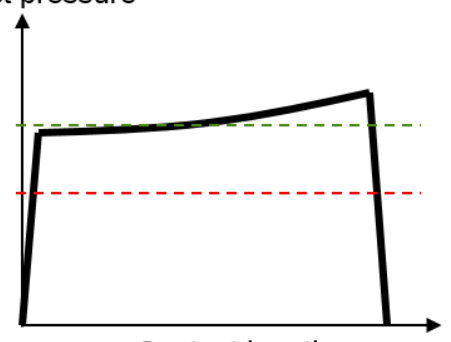

Contact length

Picture 5 - Procedure for sealing evaluation, based on contact pressure along contact length. (a) leakage, (b) risk of leakage and (c) no leakage.

As example, Picture 6 shows the graphics of contact pressure along the critical path for both test bench and engine models under minimal and maximal assembly forces and internal pressure of 2100 bar. The internal side is not critical, because leakage to internal regions is allowed. Then, only the contact pressure at external side is evaluated. At this region, the peaks of contact pressure at end of path is neglected due to numerical singularities caused by the sharp edge. Looking for the useful region, it is observed greater region with contact pressure values higher than safety limit at engine models with minimal and maximal assembly forces and at test bench model only with maximal assembly force, which means sealing function is achieved and no leakage is expected. However, at test bench model with minimal assembly force, the contact pressure values are smaller than applied internal pressure and then leakage problems can occur.

For all evaluated cases, the leakage evaluation results are shown in Table 1 . The safety factor (Sf) is calculated based on maximum contact pressure value and applied internal pressure, while the statement is according to the procedure explained above. The assembly at test bench is more critical due to the missing of injector clamping force. Under minimal nozzle nut assembly force and internal pressure of 1900 bar there is risk of leakage and under 2100 bar leakage is expected. At engine, no leakage is expected even under minimal assembly forces. Under maximum peak pressure of work conditions (1800 bar) safety factors higher than 2,0 are observed. 


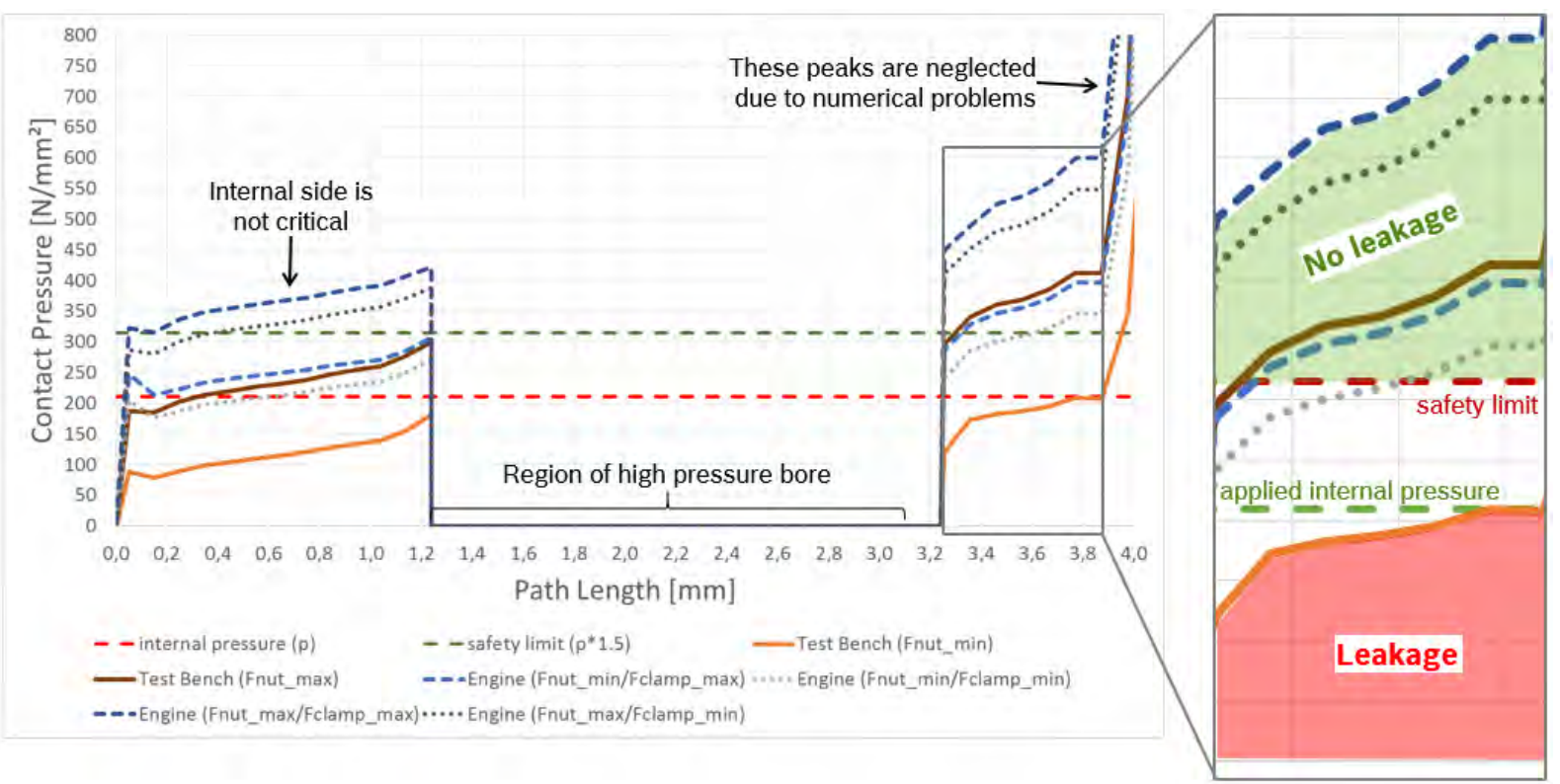

Picture 6 - Procedure for sealing evaluation, based on contact pressure along contact length. (a) leakage, (b) risk of leakage and (c) no leakage.

Table 1 - Leakage evaluation for all evaluated cases with safety factor (Sf).

\begin{tabular}{|c|c|c|c|c|}
\hline $\begin{array}{c}\text { Internal pressure } \\
\text { [bar] }\end{array}$ & $\begin{array}{c}\text { Force at } \\
\text { nozzle nut }\end{array}$ & Test Bench & $\begin{array}{c}\text { Engine } \\
\left(F_{\text {clamp_min }}\right)\end{array}$ & $\begin{array}{c}\text { Engine } \\
\left(\mathrm{F}_{\text {clamp_max }}\right)\end{array}$ \\
\hline \multirow{2}{*}{500} & $F_{\text {nut_min }}$ & $\begin{array}{l}\text { No leakage } \\
\mathrm{Sf}=5,2\end{array}$ & $\begin{array}{c}\text { No leakage } \\
\text { Sf }=7,6\end{array}$ & $\begin{array}{c}\text { No leakage } \\
\mathrm{Sf}=8,6\end{array}$ \\
\hline & Fnut_max & $\begin{array}{c}\text { No leakage } \\
\mathrm{Sf}=9,2\end{array}$ & $\begin{array}{c}\text { No leakage } \\
\text { Sf }=11,6\end{array}$ & $\begin{array}{c}\text { No leakage } \\
\text { Sf }=12,6\end{array}$ \\
\hline \multirow{2}{*}{1000} & Fnut_min & $\begin{array}{c}\text { No leakage } \\
\mathrm{Sf}=2,4\end{array}$ & $\begin{array}{c}\text { No leakage } \\
\text { Sf }=3,7\end{array}$ & $\begin{array}{c}\text { No leakage } \\
\text { Sf }=4,2\end{array}$ \\
\hline & $F_{\text {nut_max }}$ & $\begin{array}{l}\text { No leakage } \\
\mathrm{Sf}=4,5\end{array}$ & $\begin{array}{c}\text { No leakage } \\
\text { Sf }=5,7\end{array}$ & $\begin{array}{c}\text { No leakage } \\
\text { Sf }=6,2\end{array}$ \\
\hline \multirow{2}{*}{1800} & $F_{\text {nut_min }}$ & Not simulated & $\begin{array}{c}\text { No leakage } \\
\text { Sf }=2,0\end{array}$ & $\begin{array}{c}\text { No leakage } \\
\mathrm{Sf}=2,2\end{array}$ \\
\hline & $F_{\text {nut_max }}$ & Not simulated & $\begin{array}{c}\text { No leakage } \\
\text { Sf }=3,1\end{array}$ & $\begin{array}{c}\text { No leakage } \\
\text { Sf }=3,4\end{array}$ \\
\hline \multirow{2}{*}{1900} & Fnut_min & $\begin{array}{l}\text { Risk of leakage } \\
\qquad \mathrm{Sf}=1,1\end{array}$ & $\begin{array}{c}\text { No leakage } \\
\text { Sf }=1,8\end{array}$ & $\begin{array}{c}\text { No leakage } \\
\mathrm{Sf}=2,1\end{array}$ \\
\hline & $F_{\text {nut_max }}$ & $\begin{array}{c}\text { No leakage } \\
\text { Sf }=2,2\end{array}$ & $\begin{array}{c}\text { No leakage } \\
\text { Sf }=2,9\end{array}$ & $\begin{array}{c}\text { No leakage } \\
\mathrm{Sf}=3,2\end{array}$ \\
\hline \multirow{2}{*}{2100} & $F_{\text {nut_min }}$ & $\begin{array}{l}\text { Leakage } \\
\mathrm{Sf}=1,0\end{array}$ & $\begin{array}{c}\text { No leakage } \\
\text { Sf }=1,6\end{array}$ & $\begin{array}{c}\text { No leakage } \\
\text { Sf }=1,9\end{array}$ \\
\hline & Fnut_max & $\begin{array}{c}\text { No leakage } \\
\mathrm{Sf}=2,0\end{array}$ & $\begin{array}{c}\text { No leakage } \\
\mathrm{Sf}=2,6\end{array}$ & $\begin{array}{c}\text { No leakage } \\
\text { Sf }=2,9\end{array}$ \\
\hline
\end{tabular}




\section{CONCLUSIONS}

The assembly at test bench is more critical against leakage at interface between injector and nozzle bodies due to the missing clamping force of injector at engine block. Considering minimal nozzle nut assembly force, potential risk of leakage is observed at leakage tests with internal pressure higher than 1900 bar.

When injectors are assembled at engine the sealing function is achieved and no leakage is expected even considering minimal assembly forces and internal pressures higher than maximum peak pressure of working conditions.

These statements are in accordance with the results from performed leakage tests and endurance tests at engine.

Improvements at assembly condition at test bench will be implemented in order to reduce the risk of leakage and to approximate the real assembly condition at engines. 